\title{
Ibuprofen and NSAID Use in COVID-19 Infected Patients Is Not Associated with Worse Outcomes: A Prospective Cohort Study
}

\author{
Laila Carolina Abu Esba (D) - Rahaf Ali Alqahtani · Abin Thomas • \\ Nour Shamas · Lolowa Alswaidan · Gahdah Mardawi
}

Received: September 17, 2020 / Accepted: October 19, 2020 / Published online: November 2, 2020

(C) The Author(s) 2020

\begin{abstract}
Introduction: Ibuprofen disappeared from the pharmacy shelves during the 2019 coronavirus (COVID-19) pandemic. However, a while later, information circulated that ibuprofen should be avoided as it could worsen COVID-19 symptoms. The aim of our study was to assess the association of acute and chronic use of
\end{abstract}

Electronic supplementary material The online version of this article (https://doi.org/10.1007/s40121020-00363-w) contains supplementary material, which is available to authorized users.

L. C. Abu Esba $(\bowtie) \cdot$ R. A. Alqahtani .

L. Alswaidan · G. Mardawi

Pharmaceutical Care Department, Ministry of the

National Guard, Health Affairs, Riyadh, Saudi Arabia

e-mail: abuesbala@ngha.med.sa

L. C. Abu Esba · R. A. Alqahtani · N. Shamas .

L. Alswaidan · G. Mardawi

King Abdullah International Medical Research

Center, Riyadh, Saudi Arabia

L. C. Abu Esba · R. A. Alqahtani · N. Shamas .

L. Alswaidan · G. Mardawi

College of Pharmacy, King Saud Bin Abdulaziz

University for Health Sciences, Riyadh, Saudi Arabia

A. Thomas

College of Biomedical and Life Sciences, Cardiff

University, Cardiff, UK

\section{N. Shamas}

Infection Prevention and Control Department, Ministry of the National Guard, Health Affairs, Riyadh, Saudi Arabia nonsteroidal anti-inflammatory drugs (NSAIDs) with worse COVID-19 outcomes.

Methods: We did a prospective cohort study between April 12 and June 1, 2020. Adults consecutively diagnosed with COVID-19 were included. Information on NSAID use was collected through a telephone questionnaire, and patients were followed up for COVID-19 infection outcomes, including death, admission, severity, time to clinical improvement, oxygen requirement and length of stay.

Results: Acute use of ibuprofen was not associated with a greater risk of mortality relative to non-use (adjusted hazard ratio [HR] 0.632 [95\% CI $0.073-5.441 ; P=0.6758]$ ). Chronic NSAID use was also not associated with a greater risk of mortality (adjusted HR $0.492 \quad[95 \%$ CI $0.178-1.362 ; P=0.1721]$ ). Acute ibuprofen use was not associated with a higher risk of admission compared to non-NSAID users (adjusted odds ratio OR 1.271; 95\% CI 0.548-2.953). NSAID users did not have a significantly longer time to clinical improvement or length of stay. Conclusion: Acute or chronic use of ibuprofen and other NSAIDs was not associated with worse COVID-19 disease outcomes.

Keywords: COVID-19; COVID-19 outcomes; Ibuprofen; NSAIDs 


\section{Key Summary Points}

\section{Why carry out this study?}

The concern about ibuprofen and NSAID use circulating in the media during the COVID-19 outbreak was based solely on anecdotal observation, and a correspondence published in the Lancet posed the theoretical explanation that, due to the port of entry of COVID-19 that may be upregulated by some drugs, they may worsen COVID-19 outcomes.

The aim of our study was to assess the association of acute and chronic use of NSAIDs with worse COVID-19 outcomes.

\section{What was learned from the study?}

Acute ibuprofen use was not associated with a greater risk of mortality relative to nonusers (adjusted hazard ratio (HR) 0.632 [95\% CI 0.073-5.441; $P=0.6758]$ ). NSIAD chronic use was also not associated with greater risk of mortality (adjusted HR, 0.492 [95\% CI 0.178-1.362; $P=0.1721]$ ).

NSAID users did not have a significantly longer time to clinical improvement or length of hospital stay.

The proposed potential benefit of ACE2 through the removal of angiotensin II in viral-mediated lung injury possibly means that upregulating ACE2 might be beneficial, with no evidence of harm seen in our study; more research could be conducted to explore the potential repurposing of NSAIDs for COVID-19 treatment.

\section{DIGITAL FEATURES}

This article is published with digital features, including a summary slide, to facilitate understanding of the article. To view digital features for this article go to https://doi.org/10.6084/ m9.figshare.13103009.

\section{INTRODUCTION}

Ibuprofen is a nonsteroidal anti-inflammatory drug (NSAID) commonly used during any infection accompanied by fever. It is an effective antipyretic and analgesic and is available over the counter (OTC). Acetaminophen and ibuprofen are the two most extensively used antipyretics [1].

Ibuprofen disappeared from the pharmacy shelves when quarantine measures were announced to combat the 2019 coronavirus (COVID-19) disease pandemic, which led to global shortages of ibuprofen [2]. However, a while later information circulated on the news saying that ibuprofen should be avoided as it could worsen COVID-19 symptoms [3-5].

The concern with ibuprofen in the media during the COVID-19 outbreak was fueled by the Health Minister of France, who shared on social media that NSAIDs including ibuprofen could worsen COVID-19 infections [6]. This was based solely on observation, and no reference to any published data was ever made. Such opinions are influenced by indication bias as patients usually step up to ibuprofen and other NSAIDs when their symptoms get worse.

Shortly thereafter, a correspondence published in the Lancet posed the theory that due to the port of entry of COVID-19, which binds to their target cells through angiotensin-converting enzyme 2 (ACE2), some drugs that upregulate the expression of ACE2, giving ibuprofen as an example, may facilitate infection with COVID-19 [7].

Later on, many health agencies shared statements reporting that the concern with ibuprofen and other NSAIDs had no solid evidence to support the recommendations to avoid its use in COVID-19-infected patients or the general population to minimize the risk of transmission [8-11].

Nevertheless, the theory and observation are worth further research. ACE2 plays an important role in the viral entry to cells and is also an important mediator in the renin-angiotensin system, which is important in the mechanism of multiple drugs, not only ibuprofen [12]. In the search for literature related to the effect ibuprofen or NSAIDs may directly have on 
ACE2, only one animal study was found. This study was in diabetic rats and reported an increase in ACE2 in the heart tissue after treatment with ibuprofen [13]; however, a similar effect cannot be easily extrapolated to non-diabetic human patients or lung tissue.

Nevertheless, if any of these speculations and observations that ibuprofen worsens symptoms or increases the risk of transmission are true, the implications for the healthcare systems may be huge because of its wide OTC use not only in the context of COVID-19-associated fever but also in patients that chronically use it for pain $[14,15]$.

Implications of public fear based on little clinical evidence could be that patients with chronic pain switch from NSAIDs to alternatives such as opioids, which could worsen the opioid epidemic. Alternatively, if higher doses of acetaminophen are used to avoid NSAIDs, an increase in liver injury cases may occur.

Contrarily, a few animal studies demonstrated that ACE2 plays a critical role in viralinduced lung injury, showing worse survival in ACE2 knockout mice, and proposed a potential benefit of ACE2 through the removal of angiotensin II in viral-mediated lung injury $[16,17]$. This possibly means that upregulating ACE2 might be beneficial. In fact, recombinant ACE2 did seem to improve lung injury in a phase II trial involving acute respiratory distress syndrome (ARDS) patients [18].

With the theoretical, anecdotal observations and serious implications together with theories of benefit, the aim of our study was to provide an evaluation of outcomes in COVID-19-infected patients taking ibuprofen or other NSAIDs, both acutely and/or chronically, which is essential to rule out any drug safety concerns and determine whether comorbid conditions and age confound this association. In addition, results may set a path to further study whether ACE2 upregulation has a valid therapeutic potential.

\section{METHODS}

\section{Study Design and Participants}

This prospective observational cohort study took place at the Ministry of National Guard
Health Affairs (MNGHA) in Riyadh, Saudi Arabia, which includes King Abdulaziz Medical City, a 1500-bed hospital, and King Abdullah Specialist Children's Hospital, a 600-bed hospital that was also utilized for COVID-19-infected patients during the outbreak. In total, the facilities provide 100 adult intensive care unit (ICU) beds, which was increased to 200 beds during the peak of COVID-19 cases. Patients seen at the facility were MNGHA-eligible patients, MNGHA employees and later throughout the study period, as a directive from the Ministry of Health, any patient in Saudi Arabia, regardless of status, who would be eligible for treatment at any governmental hospital if infected with COVID-19.

We prospectively identified adult patients (aged $\geq 18$ years) who were diagnosed with a laboratory-confirmed case of COVID-19 from April 12 to June 1, 2020, who had a valid mobile contact number in our electronic medical records (EMR) and were willing to participate in the study. Laboratory testing for COVID-19 was done using the reverse transcription-polymerase chain reaction (RT-PCR). No sample size calculation was performed; it was determined by the study period. The list of patients with a COVID19-positive result was obtained daily throughout the study period. The study was approved by the ethics committee of King Abdullah International Medical Research Center (KAIMRC) for both participating centers, King Abdulaziz Medical City and King Abdullah Specialist Children's Hospital. The study was performed in accordance with the Helsinki Declaration of 1964 and its later amendments. A telephone consent form was developed and approved by the IRB.

\section{Exposure of Interest: Use of Ibuprofen and Other NSAIDs}

The exposure of interest was patients' acute use of ibuprofen or NSAIDs (including aspirin) during infection and chronic NSAID use before the confirmed COVID-19 infection. The exposures of interest were divided into four groups: group 1: acute ibuprofen users during infection only; group 2: other aspirin/NSAID acute use 
during infection; group 3: aspirin/NSAID chronic users; group 4: any NSAID users, acute/ chronic combined. Non-NSAID users were the control group.

Owing to the common use of these drugs as OTC medications, information about patient exposure was captured through a short telephone questionnaire in addition to electronic prescription filling information from the patient's EMR to identify chronic NSAID use. Chronic NSAID use was defined as $>1$ (30-day) filling in a 6-month period prior to the index date or patient self-reported chronic use.

All patients, whether admitted or not, were interviewed via telephone to identify OTC antipyretics used during infection and chronic aspirin/NSAID use. The questionnaire was administered within 5 days of the confirmed laboratory result to minimize the risk of recall bias. Patients who were unable to answer or had their telephone switched off were excluded from the study.

\section{Questionnaire Administered by Telephone to COVID-19-Positive Patients}

The questionnaire included questions about the onset of symptoms, whether the patient experienced fever, use of antipyretics including acetaminophen, ibuprofen or any other NSAID during the infection (patients were given a list of common brand names of ibuprofen) and chronic use of aspirin/NSAIDs within the past 6 months.

\section{Data Collection}

We recorded data from the patients' EMR on demographics, comorbidities, admission for COVID-19, electronic prescription of antipyretics including NSAIDs during infection and, within the past 6 months, standard of care received, number of antibiotics prescribed during the infection and the outcomes of interest listed below.

\section{Outcomes}

The primary outcome was 30-day mortality. Secondary analysis included severe COVID-19 infection and hospital admission.
Additional outcomes for admitted patients included time to clinical improvement, oxygen support required and length of hospital stay.

Time to clinical improvement was defined as the time from admission to an improvement of 2 points (from the status at admission) on the World Health Organization's recommended seven-category ordinal scale or live discharge from the hospital, whichever came first [19].

Additional outcome for patients not admitted included a prescription for an antibiotic during the patient's infection with COVID-19, indicating worse symptoms in patients not admitted.

Patients were followed up from the index date until primary outcome occurrence, discharge or up to 30 days.

\section{Statistical Analysis}

All descriptive statistics were reported as counts or means. For comparison of demographic variables and comorbidities among cohorts, independent-sample $t$ tests were used for numeric variables, while $\chi^{2}$ or Fisher exact tests were used for categorical variables.

We estimated hazard ratios (HRs) with 95\% confidence intervals for mortality using the Cox proportional hazards model. Log-binomial regression models were used to determine whether any of the NSAID groups were associated with an increase in the relative risk (RR) of outcomes upon adjustment for covariates. The time to clinical improvement and length of stay were portrayed by Kaplan-Meier plot and compared with a log-rank test.

Adjusted models included the following covariates: age, sex and comorbidities: hypertension, diabetes mellitus (DM), dyslipidemia, asthma or chronic obstructive pulmonary disease (COPD), cardiovascular disease (CVD), renal or liver impairment, and malignancy.

The institutional review board (IRB) at King Abdullah International Medical Research Center (KAIMRC) (protocol RC20/209/R) approved this study for both King Abdulaziz Medical City and King Abdullah Specialist Children's Hospital. A telephone consent form was developed 
and approved by the IRB; all participants verbally consented.

\section{RESULTS}

For this cohort study designed to examine outcomes among patients with COVID-19, 503
COVID-19-infected patients were included; the first patient was included on April 12, 2020, and the last on June 1, 2020. Baseline characteristics of the study groups are shown in Table 1 . Patient selection is shown in Fig. 1. Overall, $17 \%$ of patients were asymptomatic, $70 \%$ reported mild symptoms, $7 \%$ were considered moderate, and $6 \%$ were severe.

Table 1 Baseline characteristics of patients with COVID-19 by NSAID user groups and non-NSAID users

\begin{tabular}{|c|c|c|c|c|c|}
\hline Characteristics & $\begin{array}{l}\text { Group } 1^{a}(n=40 \\
[7.9 \%])\end{array}$ & $\begin{array}{l}\text { Group } 2^{b}(n=17 \\
[3.4 \%])\end{array}$ & $\begin{array}{l}\text { Group } 3^{c}(n=96 \\
[19 \%])\end{array}$ & $\begin{array}{c}\text { Group } 4^{d} \\
(n=146 \\
[29 \%])\end{array}$ & $\begin{array}{l}\text { Group } 5^{\mathrm{e}}(n=357 \\
[71 \%])\end{array}$ \\
\hline \multicolumn{6}{|l|}{ Sex } \\
\hline Male $(n=288)$ & $23(57.5)$ & $8(47.06)$ & $51(53.1)$ & $76(52)$ & $212(59.4)$ \\
\hline Female $(n=215)$ & $17(42.5)$ & $9(52.94)$ & $45(46.9)$ & $70(48)$ & $145(40.6)$ \\
\hline Age, median (IQR) & $34.5(27-43.5)$ & $38(34-44)$ & $57(38.5-67.5)$ & $\begin{array}{l}47.5 \\
\quad(33-63)\end{array}$ & $36(27-49)$ \\
\hline Comorbidities & $16(40)$ & $8(47)$ & $76(79.2)$ & $97(66.4)$ & $119(33.3)$ \\
\hline $\begin{array}{l}\text { Hypertension } \\
\qquad(n=103)\end{array}$ & $2(5)$ & $2(11.8)$ & $49(51)$ & $51(34.9)$ & $52(14.6)$ \\
\hline Diabetes $(n=113)$ & $3(7.5)$ & $3(17.7)$ & $56(58.3)$ & $60(41.1)$ & $53(14.8)$ \\
\hline $\begin{array}{l}\text { Dyslipidemia } \\
\quad(n=88)\end{array}$ & $4(10)$ & $1(5.9)$ & $41(42.7)$ & $45(30.8)$ & $43(12)$ \\
\hline $\begin{array}{l}\text { Asthma or COPD } \\
\quad(n=26)\end{array}$ & $4(10)$ & 0 & $10(10.4)$ & $13(8.9)$ & $13(3.6)$ \\
\hline $\operatorname{CVD}(n=27)$ & 0 & $1(5.9)$ & $17(17.7)$ & $18(12.3)$ & $9(2.5)$ \\
\hline $\begin{array}{l}\text { Renal impairment } \\
\quad(n=16)\end{array}$ & 0 & 0 & $6(6.3)$ & $6(4.1)$ & $10(2.8)$ \\
\hline $\begin{array}{l}\text { Liver impairment } \\
\qquad(n=6)\end{array}$ & 0 & 0 & $1(1)$ & $1(0.7)$ & $5(1.4)$ \\
\hline Malignancy $(n=7)$ & 0 & $1(5.9)$ & $3(3.1)$ & $4(2.7)$ & $3(0.8)$ \\
\hline $\begin{array}{l}\text { Hypothyroidism } \\
\quad(n=\end{array}$ & $2(5)$ & 0 & $5(5.2)$ & $7(5)$ & $7(2)$ \\
\hline
\end{tabular}

COPD chronic obstructive pulmonary disease, COVID-19 coronavirus disease 2019, CVD cardiovascular disease, IQR interquartile range, NSAID nonsteroidal anti-inflammatory drugs

${ }^{a}$ Group 1: patients that used ibuprofen only during infection

${ }^{b}$ Group 2: Other aspirin/NSAID acute use during infection

c Group 3: chronic NSAID users

${ }^{d}$ Group 4: acute and chronic NSAID users combined

e Group 5: non-NSAID user 


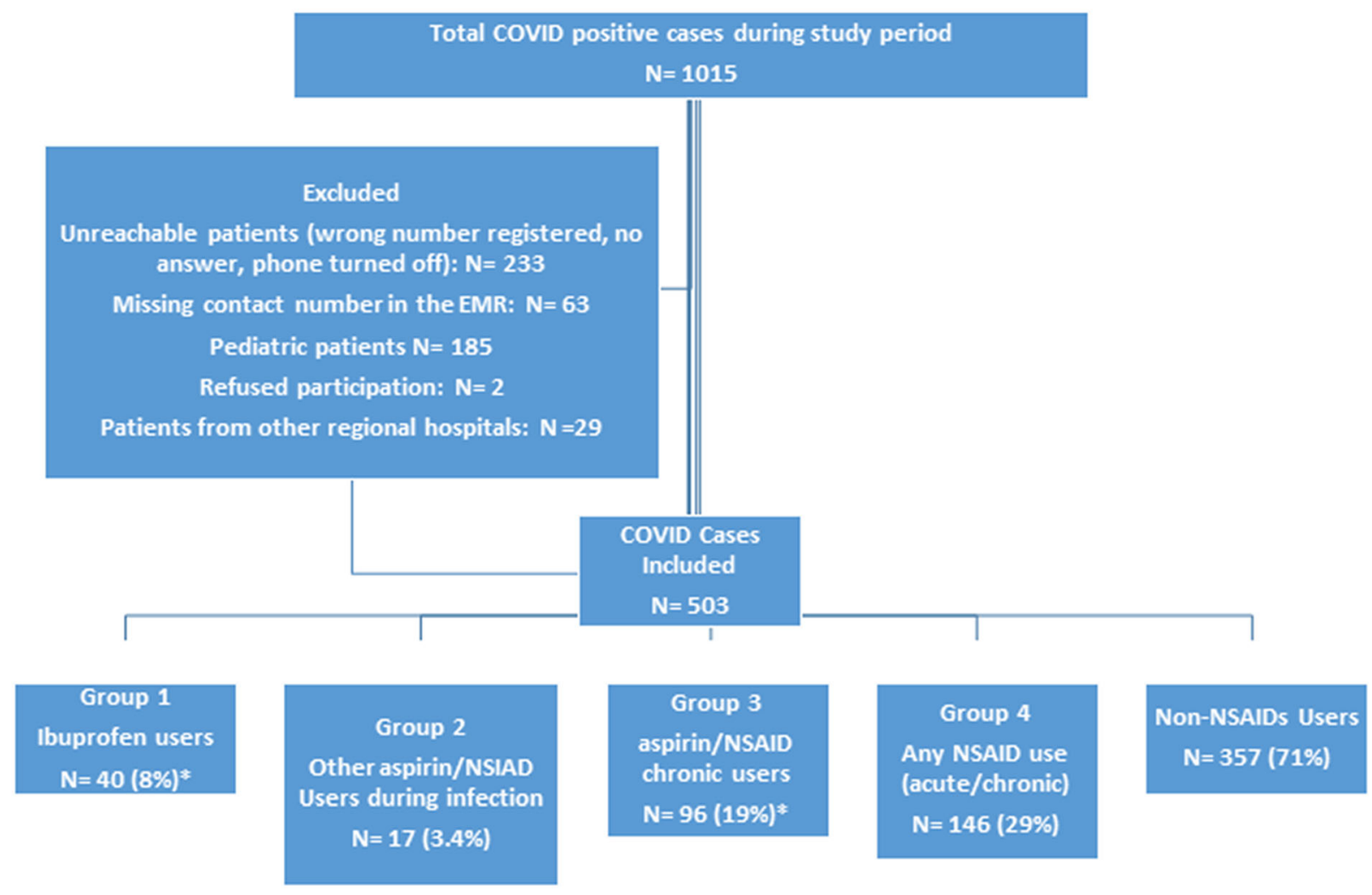

Fig. 1 Patient selection. NSAID nonsteroidal anti-inflammatory drugs, COVID-19 coronavirus disease 2019, EMR electronic medical record, $N$ number. ${ }^{*}$ Seven $(1.4 \%)$

Of the 503 patients included, 40 (7.95\%) used ibuprofen during infection (group 1), 17 (3.4\%) used other NSAIDs during infection (group 2), 96 (19\%) used NSAIDs chronically before infection (group 3), 146 (29\%) had any NSAID use, with acute and/or chronic users combined (group 4), and 357 (71\%) were nonNSAID users. Seven patients $(1.4 \%)$ were both chronic users of NSAIDs and used ibuprofen acutely during their infection. (Table 1).

Chronic NSAID users were older than nonNSAID users (57 years [IQR 38.5-67.5] vs. 36 years [IQR 27-49]). Chronic NSAID users were more likely to have comorbid conditions than non-NSAID users (e.g., $41 \%$ vs. $14.8 \%$ with DM and $12.3 \%$ vs. $2.5 \%$ with CVD). NSAID use was slightly higher in men than in women $(52 \%$ vs. $48 \%$ ).

For the type of NSAIDs used, see supplemental Tables 1 and 2. For other COVID-19- patients were both chronic users of NSAIDs and used ibuprofen acutely during their infection

related supportive drugs used in this cohort of patients, see supplemental Table 3 .

Antibiotic, oseltamivir and acetaminophen use was higher in all NSAID user groups compared to non-NSAID users, as shown in supplemental Table 3. The mean accumulative dose of ibuprofen in group 1 was $3575 \mathrm{mg}$ (SD 3421), and the mean number of days of treatment with ibuprofen was 3.3 days (SD 2.2).

\section{Mortality}

A total of 18 (3.8\%) patients died during the study period in the cohort of patients included: $2.5 \%$ died in group 1, 5.9\% in group 2, 6.3\% in group 3, $4.8 \%$ in group 4 and $3.1 \%$ in the nonNSAID users. Table 2 shows the unadjusted and adjusted HRs from the Cox regression analysis.

Acute ibuprofen use during infection was not associated with a greater risk of mortality 


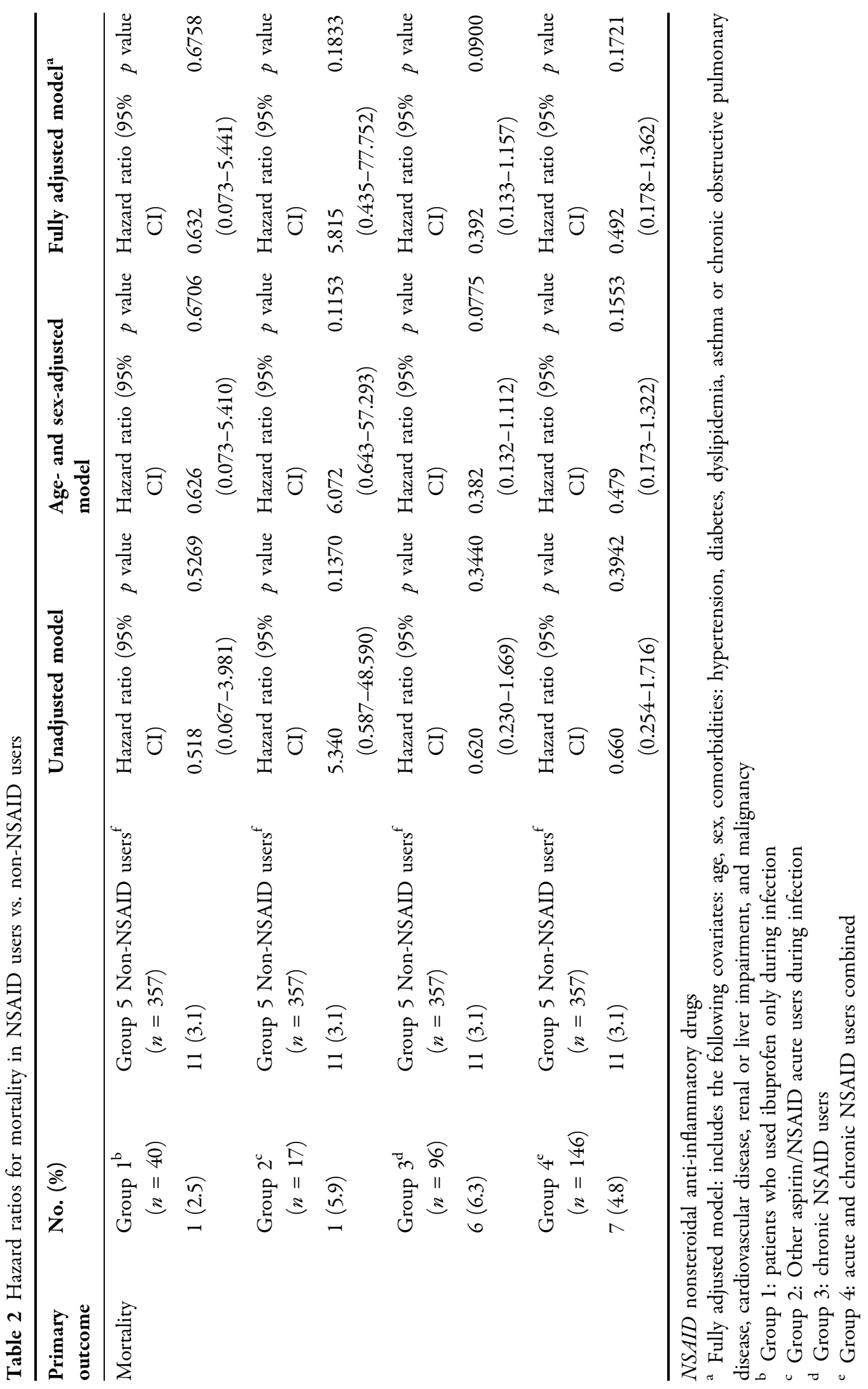


Table 3 Relative risk of mortality, admission, oxygen support and severe COVID-19 in acute ibuprofen users

\begin{tabular}{|c|c|c|c|c|c|c|}
\hline & $\begin{array}{l}\text { Unadjusted } \\
\text { Relative risk }\left(95 \% \mathrm{CI}^{\dagger}\right)\end{array}$ & $p$ value & $\begin{array}{l}\text { Age-, sex-adjusted } \\
\text { Relative risk }\left(95 \% \mathrm{CI}^{\dagger}\right)\end{array}$ & $p$ value & $\begin{array}{l}\text { Fully adjusted }^{\mathrm{a}} \\
\text { Relative risk }\left(95 \% \mathrm{CI}^{\dagger}\right)\end{array}$ & $p$ value \\
\hline Mortality & $0.6809(0.0906-5.1162)$ & 0.7087 & $2.6926(0.3293-22.0175)$ & 0.3555 & $2.6951(0.3302-21.9964)$ & 0.3547 \\
\hline Admission & $0.9138(0.4636-1.8013)$ & 0.7946 & $1.2625(0.6340-2.5140)$ & 0.5072 & $1.1819(0.5917-2.3606)$ & 0.6359 \\
\hline $\begin{array}{l}\text { Oxygen } \\
\text { support }\end{array}$ & $0.8904(0.2752-2.8812)$ & 0.8463 & $1.5232(0.4603-5.0408)$ & 0.4907 & $1.4482(0.4361-4.8089)$ & 0.5454 \\
\hline $\begin{array}{l}\text { Severe } \\
\text { COVID- } \\
19\end{array}$ & $0.8574(0.2039-3.6056)$ & 0.8337 & $1.9180(0.4377-8.4039)$ & 0.3876 & $1.8484(0.4202-8.1314)$ & 0.4163 \\
\hline
\end{tabular}

COVID-19 coronavirus disease 2019

a Fully adjusted model, which includes the following covariates: age, sex, comorbidities: hypertension, diabetes, dyslipidemia, asthma or chronic obstructive pulmonary disease, cardiovascular disease, renal or liver impairment and malignancy

* Confidence interval

relative to non-NSAID users in the unadjusted analysis (HR $0.518 \quad[95 \%$ CI $0.067-3.981]$; $P=0.5269)$ and was not significant after adjusting for age, sex and comorbidities (HR 0.632 [95\% CI 0.073-5.441]; $P=0.6758$ ).

In addition, chronic NSAID use was not associated with greater risk of mortality relative to non-NSIAD users in the unadjusted analysis (HR 0.660 [95\% CI 0.254-1.716]; $P=0.3942$ ) and not significant after accounting for age, sex and comorbidities (HR $0.492 \quad[95 \%$ CI 0.178-1.362]; $P=0.1721)$.

\section{Relative Risk of Mortality, Admission, Oxygen Support and Severe COVID-19 Disease}

The adjusted RR of mortality, admission, oxygen support and severe COVID-19 disease in acute ibuprofen users (group 1) was not significantly higher than in non-NSAID users (Table 3).

The adjusted RR of mortality in acute/ chronic NSAID users combined (group four) was not significantly higher than that of non-NSIAD

Table 4 Relative risk of death, admission, oxygen support and severe COVID-19 disease in acute and chronic NSAID users combined

\begin{tabular}{|c|c|c|c|c|c|c|}
\hline & $\begin{array}{l}\text { Unadjusted } \\
\text { Relative risk }\left(95 \% \mathrm{CI}^{\ddagger}\right)\end{array}$ & $p$ value & $\begin{array}{l}\text { Age-, sex-adjusted } \\
\text { Relative risk }\left(95 \% \mathrm{CI}^{\ddagger}\right)\end{array}$ & $p$ value & $\begin{array}{l}\text { Fully adjusted }{ }^{\text {a }} \\
\text { Relative risk }\left(95 \% \mathrm{CI}^{\ddagger}\right)\end{array}$ & $p$ value \\
\hline Death & $1.556(0.6032-4.0139)$ & 0.3605 & $0.6653(0.2558-1.7303)$ & 0.4034 & $0.5927(0.2261-1.5536)$ & 0.2874 \\
\hline Admission & $2.4058(1.6895-3.4258)$ & $<0.0001$ & $1.7450(1.2017-2.5341)$ & 0.0034 & $1.5419(1.0605-2.2420)$ & 0.0234 \\
\hline $\begin{array}{l}\text { Oxygen } \\
\text { support }\end{array}$ & $1.8339(0.9953-3.3790)$ & 0.0518 & $1.0182(0.5351-1.9371)$ & 0.9563 & $0.9189(0.4818-1.7525)$ & 0.7975 \\
\hline $\begin{array}{l}\text { Severe } \\
\text { COVID- } \\
19\end{array}$ & $1.7260(0.8244-3.6139)$ & 0.1477 & $0.8289(0.3870-1.7756)$ & 0.6293 & $0.7282(0.3398-1.5605)$ & 0.4147 \\
\hline
\end{tabular}

COVID-19 coronavirus disease 2019, NSAID nonsteroidal anti-inflammatory drugs

${ }^{a}$ Fully adjusted model, including the following covariates: age, sex, comorbidities: hypertension, diabetes, dyslipidemia, asthma or chronic obstructive pulmonary disease, cardiovascular disease, renal or liver impairment, and malignancy

$\$$ Confidence interval 


\section{Estimates and $95 \%$ CI of Relative Risks among NSAID users}

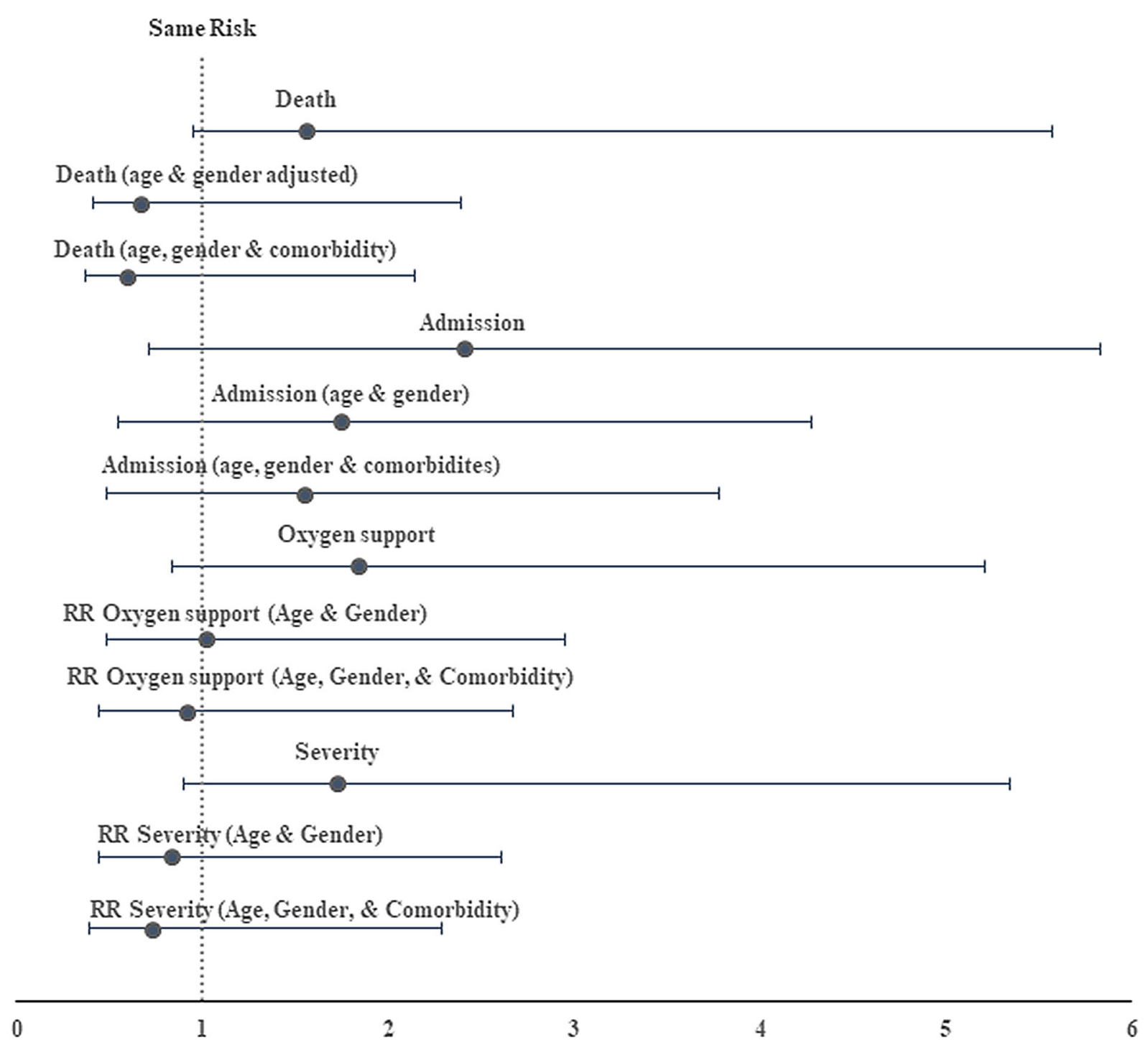

Fig. 2 Relative risk for death, admission, oxygen support requirement and severity, unadjusted and adjusted, for any NSAID use (group $4^{\mathrm{a}}$ ) vs. non-NSAID users. NSAID

users (RR 0.5927 [95\% CI $0.2261-1.5536]$; $P=0.2874)$; similarly, NSAID users were not at a higher risk of oxygen support requirement and severe COVID-19 disease compared to nonNSAID users. See Table 4 for unadjusted and adjusted RRs of outcomes in acute/chronic NSAID users (group 4). Figure 2 shows unadjusted and adjusted RRs for the different outcomes in NSIAD users (group 4).

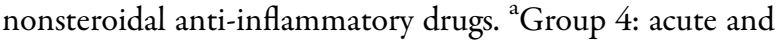
chronic NSAID users combined

\section{Admission}

In our cohort, $22.5 \%$ of patients in group 1 , $35.3 \%$ in group $2,49 \%$ in group 3 and $41.8 \%$ in group 4 were admitted vs. $17.4 \%$ in the nonNSAID user group. The adjusted RR of admission was higher in acute/chronic NSAID users (group 4) compared to non-NSAID users (RR 1.5419 [95\% CI 1.0605-2.2420]; $P=0.0234$ ). 


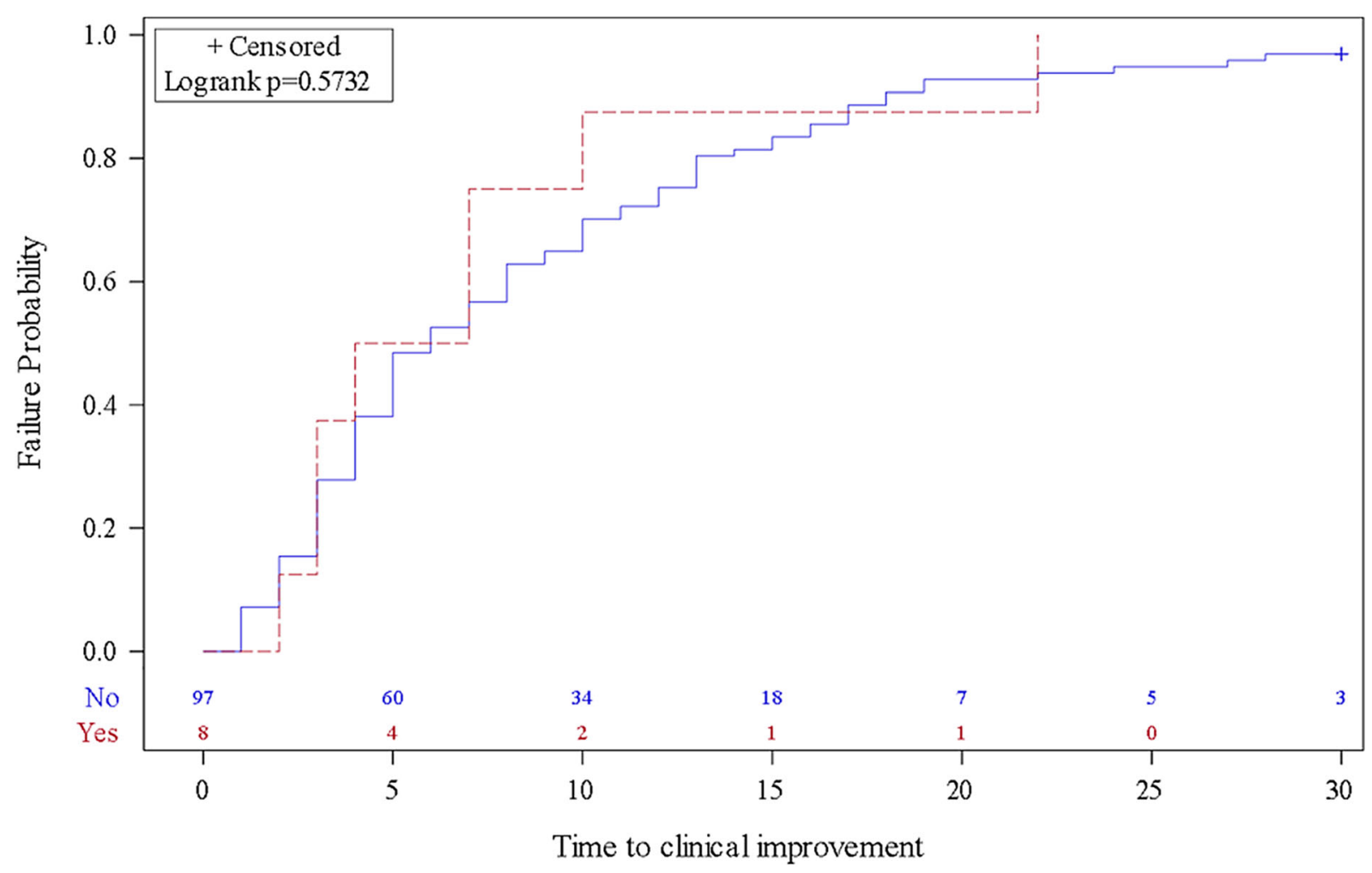

Ibuprofen Acute Use

No ------ Yes

Fig. 3 Kaplan-Meier plot for time to clinical improvement: iburpofen use (Group $1^{\text {a }}$ ) vs. non-NSAID users. NSAID nonsteroidal anti-inflammatory drugs. ${ }^{a}$ Group 1: patients that used ibuprofen only during infection

Odds of Admission for Ibuprofen Users (Group 1)

Acute ibuprofen use was not associated with a higher risk of admission compared to nonNSAID users (adjusted odds ratio OR 1.271; [95\% CI 0.548-2.953]). The OR for admission was however higher with age (OR 1.038; 95\% CI 1.021-1.055) and comorbidities (OR 3.276; 95\% CI 1.916-5.601).

\section{Time to Clinical Improvement}

There was no difference in time to clinical improvement between any NSAID user groups compared to non-NSAID users; see Figs. 3, 4 and 5. KM plots for time to clinical improvement in each group. Time to clinical improvement in acute ibuprofen users did not significantly differ from that of non-NSAID users (median 5.50 days vs. 6 days; adjusted HR 0.998; 95\% confidence interval [CI $]$ 0.474-2.101; $P=0.9963)$, in NSAID chronic users vs. nonNSAID users (median, 6 days vs. 5 days; adjusted HR for clinical improvement, 1.000; 95\% confidence interval [CI] $0.646-1.549 ; P=0.9991$ ) and iin acute/chronic NSAID users combined vs. non-NSAID users (median, 6 days vs. 5 days; adjusted HR for clinical improvement, 0.996; 95\% confidence interval [CI] 0.667-1.487; $P=0.9857)$.

\section{Length of Hospital Stay}

There was no significant difference between the length of stay in acute/chronic NSAID users compared to non-NSAID users (median, 7 days vs. 8 days; adjusted hazard ratio for the length of stay, $1.091 ; P=0.6353)$. See the KM plot for the length of stay (Fig. 6). 


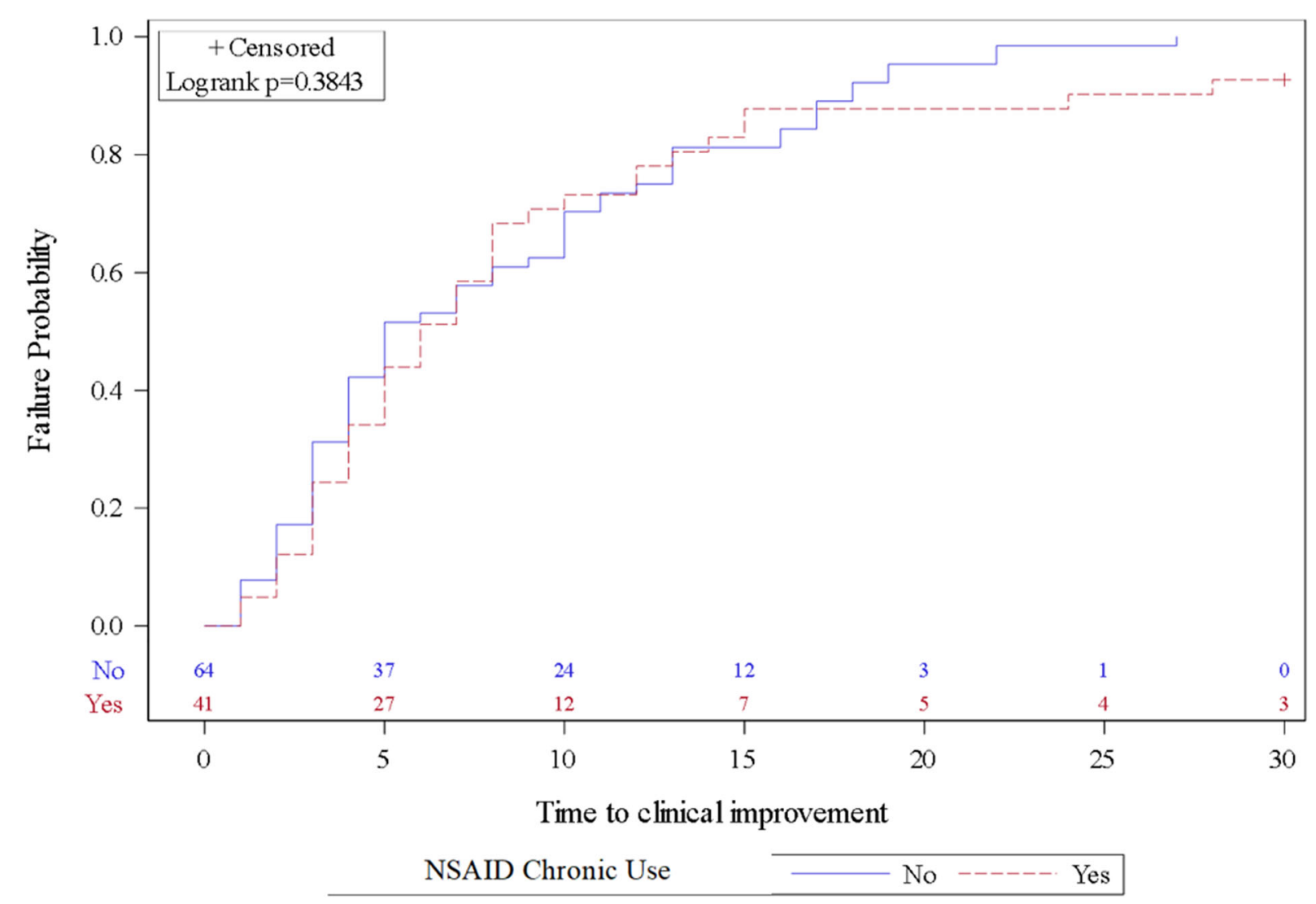

Fig. 4 Kaplan-Meier plot for time to clinical improvement: NSAID chronic use (group $3^{a}$ ) vs. non-NSAID users. NSAID

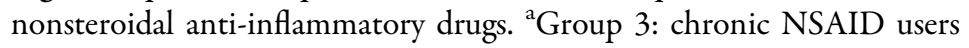

\section{Antibiotic Use}

Of the 380 patients who were not admitted, 100 (26.3\%) were prescribed an antibiotic; $24(6.3 \%)$ of them had more than one antibiotic prescription. Acute ibuprofen users and chronic NSIAD users were not prescribed antibiotics significantly more than non-NSAID users (adjusted RR $1.5475(0.8153-2.9372)] ; P=0.1817)$ and (adjusted RR $1.1536 \quad(0.6802-1.9567)]$; $P=0.5960)$, respectively. (Table 5).

\section{DISCUSSION}

Despite the risk of indication bias, not favoring outcomes in patients taking ibuprofen, as patients with more severe symptoms would probably be more likely to take it, we found no association between the acute use of ibuprofen during infection with any of the outcomes assessed including mortality, admission, severity and length of hospital stay.

We also found no association between the acute and chronic use of NSAIDs and a higher risk of mortality, severe COVID-19 disease and need for oxygen support, with no difference in time to clinical improvement and length of hospital stay compared to non-NSAID users in admitted patients. Although there was a higher risk of admission among chronic NSAID users, this outcome may have been confounded by patients admitted for concomitant conditions requiring medical care as we did not exclude patients who were admitted for other reasons and happened to be COVID-19 positive. In addition, in the early stages of this study, patients at MNGHA were admitted regardless of the severity of symptoms while waiting to be transferred to quarantine. 


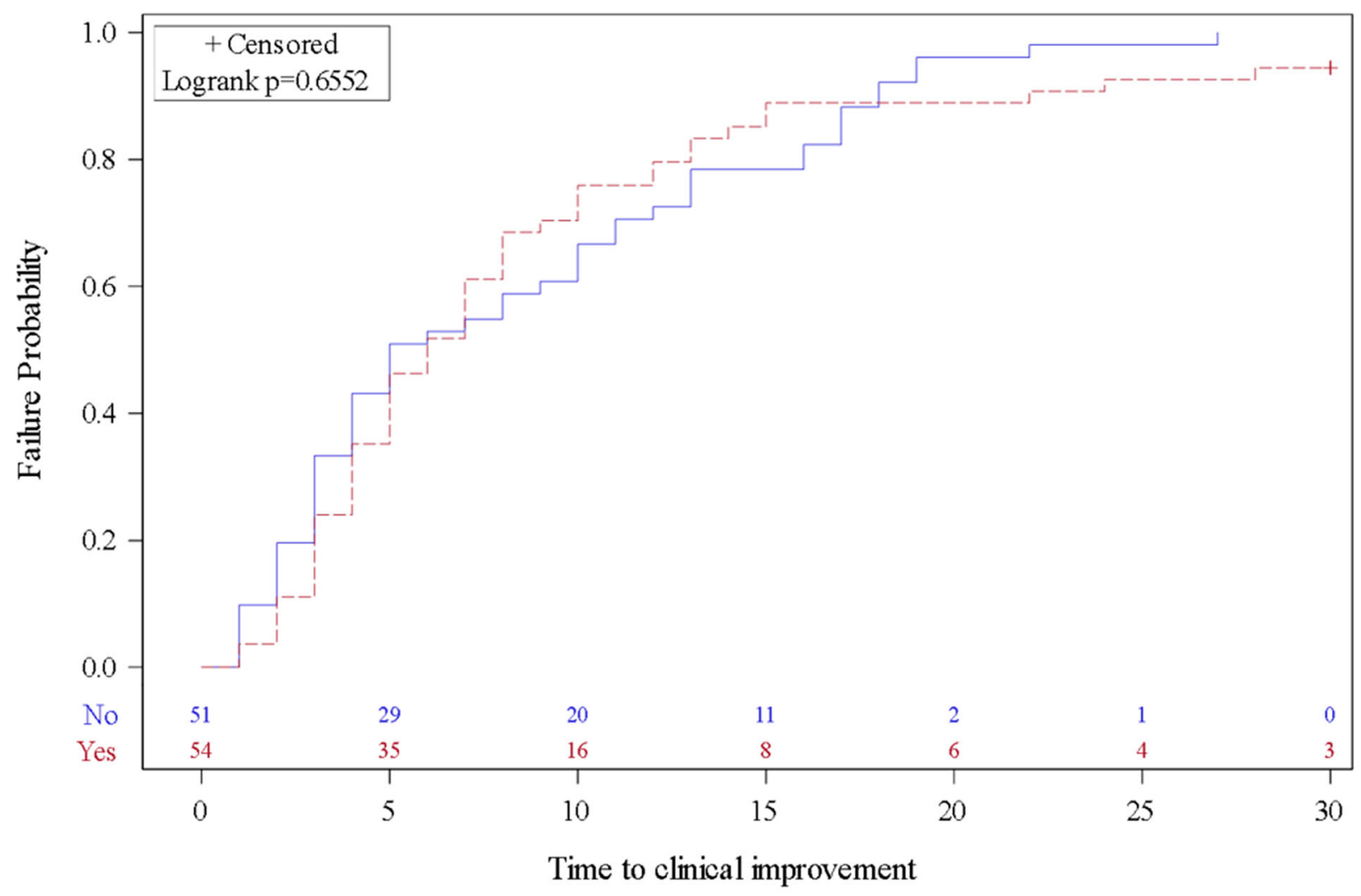

Any NSAID exposure

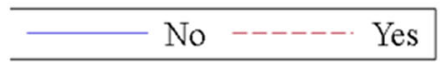

Fig. 5 Kaplan-Meier plot for time to clinical improvement: any NSAID use (group $4^{a}$ ) vs. non-NSAID users. NSAID

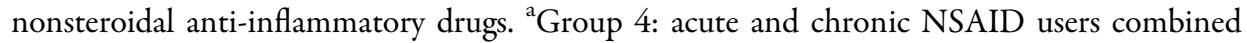

Concern about NSAIDs worsening lung infection is not new or specific to COVID-19; in fact, previous pharmacoepidemiologic data and pharmacovigilance analysis report that NSAID exposure increases the risk of severe pulmonary complications, supported by experimental data and pharmacologic plausibility [20]. These concerns and analyses were led by the French Regional Pharmacovigilance Centers, possibly explaining why early alerts on ibuprofen in COVID-19 came from France.

In a study published early on in the COVID19 pandemic, samples of plasma of infected patients had significantly higher angiotensin II levels compared to healthy individuals. The levels were linearly associated with viral load and lung injury. In addition, the authors suggested angiotensin receptor blocker (ARB) drugs as potential repurposing treatments for COVID19 [21]. This study contradicts the theory that upregulation of ACE2 is associated with adverse outcomes, as ACE2 acts as a negative regulator and decreases angiotensin II levels. Therefore, a clinical trial to test the benefit of ibuprofen in COVID-19 patients is currently ongoing [22]. An excellent narrative review outlines the theories and evidence on the mechanistic effect of ibuprofen on ACE2 [23].

Other NSAIDs such as naproxen have also been studied for their antiviral potential and showed potent in vitro activity against severe acute respiratory syndrome-related coronavirus (SARS-CoV) [24] and antiviral activity against influenza $\mathrm{A}$ and $\mathrm{B}$ viruses in animal models $[25,26]$. This is why naproxen has also been listed as a potential agent and is currently being studied in a clinical trial in COVID-19-infected patients $[27,28]$.

Our study has several limitations. First, this was an observational study; no causal 


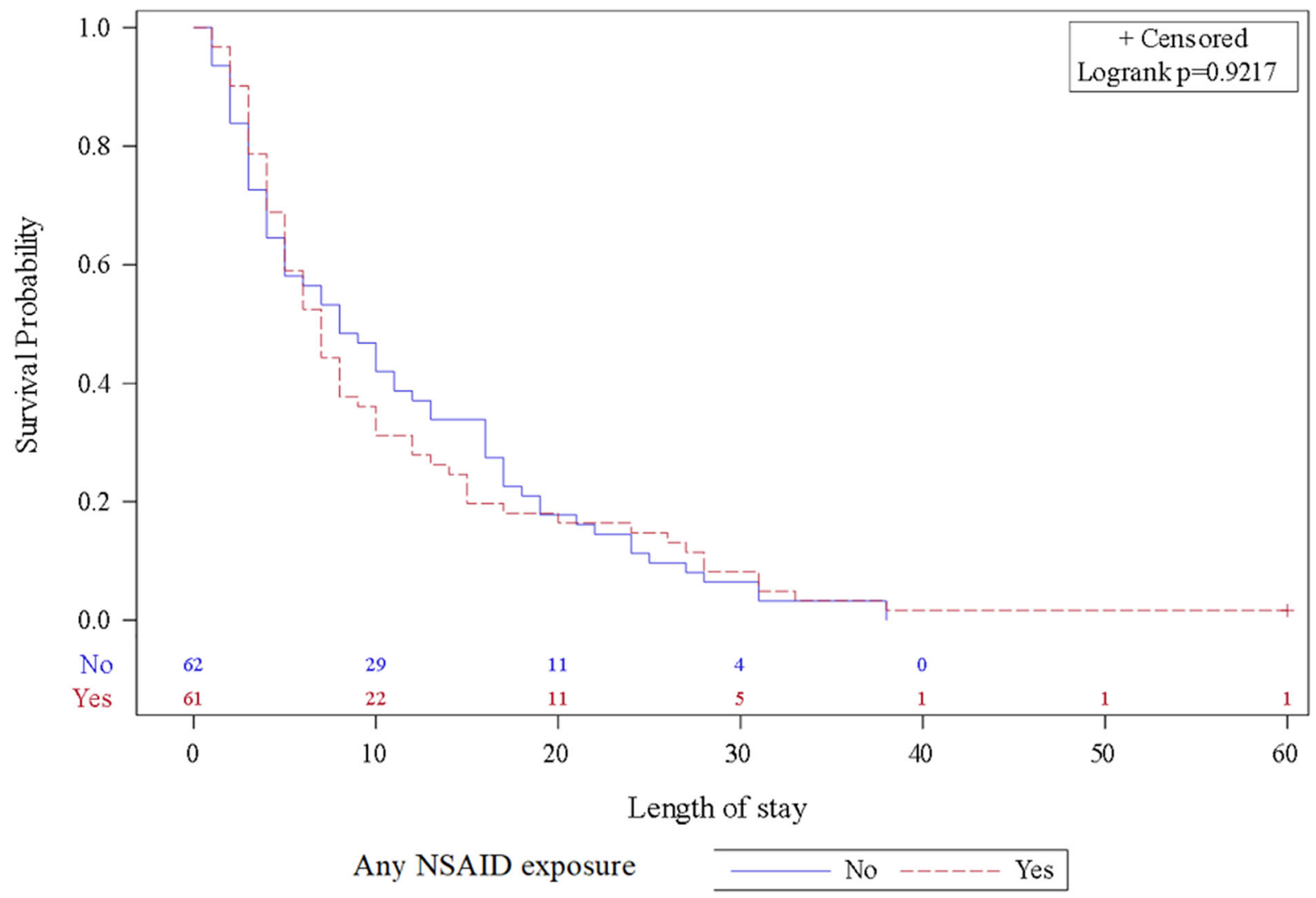

Fig. 6 Kaplan-Meier plot for length of stay in any NSAID user (group $4^{a}$ ) vs. non-NSIAD users. NSAID nonsteroidal antiinflammatory drugs. ${ }^{a}$ Group 4 : acute and chronic NSAID users combined

Table 5 Relative risk of antibiotic prescribing in NSAID users

\begin{tabular}{|c|c|c|c|c|c|c|}
\hline & $\left(95 \% \mathrm{CI}^{\ddagger}\right)$ & & $\begin{array}{l}\mathrm{d} \\
\left.\% \mathrm{CI}^{\ddagger}\right)\end{array}$ & & $\mathrm{d}^{\mathrm{a}}\left(95 \% \mathrm{CI}^{\ddagger}\right)$ & de \\
\hline & & & & & & \\
\hline roup 3 & $1.6888(1.0346-2.7566)$ & 0.0361 & $12540(07012211)$ & 0.3965 & $1.1536(0.6802-1.9567)$ & 0.5960 \\
\hline 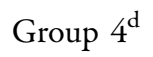 & $.7879(1.1821-2.7041)$ & 0.005 & $1.5720\left(1.0255-2.409^{\prime}\right.$ & 0.037 & $1.4351(0.9272-2.2214)$ & 0.10 \\
\hline
\end{tabular}

NSAID nonsteroidal anti-inflammatory drugs

${ }^{a}$ Fully adjusted model, which includes the following covariates: age, sex, comorbidities: hypertension, diabetes, dyslipidemia, asthma or chronic obstructive pulmonary disease, cardiovascular disease, renal or liver impairment, and malignancy

${ }^{\mathrm{b}}$ Group 1: patients that used ibuprofen only during infection

c Group 3: chronic NSAID users

d Group 4: acute and chronic NSAID users combined

conclusion can be reached, and connections should be interpreted as associations. Second, as this study was conducted at an early stage of the pandemic outbreak in Saudi Arabia, screening strategies in the beginning may have introduced selection bias relative to strategies at a later period. Third, the main analysis of this study compared NSAID users with non-NSAID 
users, but confounding by indication may have influenced the results.

However, the study strength is that prescription fillings, patient questionnaires and inhospital electronic administration records were used to confirm exposure to NSAIDs.

\section{CONCLUSION}

This study found no association between ibuprofen or any other NSAID and worse COVID-19 outcomes. Both acute and chronic exposure to NSAIDs did not show any significant association with COVID-19-related mortality, and no significant difference in time to clinical improvement or length of stay compared to non-NSAID users was found.

\section{ACKNOWLEDGMENTS}

Funding. No funding was provided for the research or writing of this manuscript. The Rapid Service Fees were funded by King Abdullah International Medical Research Center (KAIMRC).

Authorship. All named authors meet the International Committee of Medical Journal Editors (ICMJE) criteria for authorship for this article, take responsibility for the integrity of the work as a whole, and have given their approval for this version to be published.

Disclosures. Laila Carolina Abu Esba, Rahaf Ali Alqahtani, Abin Thomas, Nour Shamas, Lolowa Alswaidan and Gahdah Mardawi have no conflicts of interest to declare.

Compliance with Ethics Guidelines. The study has received approval from the ethics committee of King Abdullah International Medical Research Center (KAIMRC) for both participating centers, King Abdulaziz Medical City and King Abdullah Specialist Children's Hospital. The study was performed in accordance with the Helsinki Declaration of 1964 and its later amendments. A telephone consent form was developed and approved by the IRB.

Data Availability. The datasets generated during and/or analyzed during the current study are available from the corresponding author on reasonable request.

Open Access. This article is licensed under a Creative Commons Attribution-NonCommercial 4.0 International License, which permits any non-commercial use, sharing, adaptation, distribution and reproduction in any medium or format, as long as you give appropriate credit to the original author(s) and the source, provide a link to the Creative Commons licence, and indicate if changes were made. The images or other third party material in this article are included in the article's Creative Commons licence, unless indicated otherwise in a credit line to the material. If material is not included in the article's Creative Commons licence and your intended use is not permitted by statutory regulation or exceeds the permitted use, you will need to obtain permission directly from the copyright holder. To view a copy of this licence, visit http://creativecommons.org/licenses/by$\mathrm{nc} / 4.0 /$.

\section{REFERENCES}

1. Times P. Managing and Treating Fever: A Guide to Nonprescription Antipyretics 2018. https://www. pharmacytimes.com/publications/issue/2018/Febru ary2018/managing-and-treating-fever-a-guide-tononprescription-antipyretics. Accessed 19 March 2020 .

2. Chandler M. Global ibuprofen shortage hits UK supermarkets-with shelves left empty. 2019. https://www.mirror.co.uk/news/uk-news/global-ibu profen-shortage-hits-uk-20465178. Accessed 1 April 2020.

3. News B. Coronavirus and ibuprofen: separating fact from fiction. 2020. https://www.bbc.com/news/ 51929628. Accessed 1 April 2020.

4. Today U. Fact check: does using ibuprofen when you have coronavirus make symptoms worse? 2020. https://www.usatoday.com/story/news/factcheck/ 2020/03/18/fact-check-coronavirus-and-ibuprofen- 
do-nsaids-make-coronavirus-worse/2865866001/. Accessed 1 April 2020.

5. News N. Concerned about taking ibuprofen for coronavirus symptoms? Here's What Experts Say. 2020. https://www.npr.org/sections/health-shots/ 2020/03/18/818026613/advice-from-france-to-avo id-ibuprofen-for-covid-19-leaves-experts-baffled. Accessed 1 April 2020.

6. Willsher K. Anti-inflammatories may aggravate Covid-19, France advises. 2020. https://www. theguardian.com/world/2020/mar/14/anti-inflam matory-drugs-may-aggravate-coronavirus-infection. Accessed 1 April 2020.

7. Fang L, Karakiulakis G, Roth M. Are patients with hypertension and diabetes mellitus at increased risk for COVID-19 infection? Lancet Respir Med. 2020;8(4):e21.

8. Agency EM. EMA gives advice on the use of nonsteroidal anti-inflammatories for COVID-19. 2020. https://www.ema.europa.eu/en/news/ema-givesadvice-use-non-steroidal-anti-inflammatoriescovid-19. Accessed 3 May 2020.

9. Castro VM, Ross RA, McBride SM, Perlis RH. Identifying common pharmacotherapies associated with reduced COVID-19 morbidity using electronic health records. medRxiv. 2020. https://doi.org/10. $1101 / 2020.04 .11 .20061994$

10. DRUG USF. FDA advises patients on use of nonsteroidal anti-inflammatory drugs (NSAIDs) for COVID-19. 2020. https://www.fda.gov/drugs/drugsafety-and-availability/fda-advises-patients-use-non -steroidal-anti-inflammatory-drugs-nsaids-covid-19. Accessed 3 May 2020.

11. GOV.UK. Commission on Human Medicines advice on ibuprofen and coronavirus (COVID-19). 2020. https://www.gov.uk/government/news/commissi on-on-human-medicines-advice-on-ibuprofen-andcoronavirus-covid-19. Accessed 3 May 2020.

12. Wan Y, Shang J, Graham R, Baric RS, Li F. Receptor recognition by the novel coronavirus from Wuhan: an analysis based on decade-long structural studies of SARS coronavirus. J Virol. 2020;94(7):e00127-20. PMID: 31996437; PMCID: PMC7081895. https:// doi.org/10.1128/JVI.00127-20

13. Qiao W, Wang C, Chen B, Zhang F, Liu Y, Lu Q, et al. Ibuprofen attenuates cardiac fibrosis in streptozotocin-induced diabetic rats. Cardiology. 2015;131(2):97-106.

14. Paulose-Ram R, Hirsch R, Dillon C, Gu Q. Frequent monthly use of selected non-prescription and prescription non-narcotic analgesics among US adults. Pharmacoepidemiol Drug Saf. 2005;14(4):257-66.
15. Curhan GC, Bullock AJ, Hankinson SE, Willett WC, Speizer FE, Stampfer MJ. Frequency of use of acetaminophen, nonsteroidal anti-inflammatory drugs, and aspirin in US women. Pharmacoepidemiol Drug Saf. 2002;11(8):687-93.

16. Yang P, Gu H, Zhao Z, Wang W, Cao B, Lai C, et al. Angiotensin-converting enzyme 2 (ACE2) mediates influenza H7N9 virus-induced acute lung injury. Sci Rep. 2014;4:7027.

17. Kuba K, Imai Y, Rao S, Gao H, Guo F, Guan B, et al. A crucial role of angiotensin converting enzyme 2 (ACE2) in SARS coronavirus-induced lung injury. Nat Med. 2005;11(8):875-9.

18. Khan A, Benthin C, Zeno B, Albertson TE, Boyd J, Christie JD, et al. A pilot clinical trial of recombinant human angiotensin-converting enzyme 2 in acute respiratory distress syndrome. Crit Care. 2017;21(1):1-9.

19. Worl Health Organization WH. R\&D Blueprint and COVID-19. 2020. https://www.who.int/teams/ blueprint/covid-19. Accessed 12 June 2020.

20. Micallef J, Soeiro T, Jonville-Béra AP. French Society of Pharmacology, Therapeutics (SFPT). Non-steroidal anti-inflammatory drugs, pharmacology and COVID-19 infection. Therapies. 2020;75(4):355362. https://doi.org/10.1016/j.therap.2020.05.003

21. Liu Y, Yang Y, Zhang C, Huang F, Wang F, Yuan J, et al. Clinical and biochemical indexes from 2019-nCoV infected patients linked to viral loads and lung injury. Sci China Life Sci. 2020;63(3): 364-74.

22. ClinicalTrials.gov. LIBERATE Trial in COVID-19 (LIBERATE). 2020. https://clinicaltrials.gov/ct2/ show/NCT04334629. Accessed 12 June 2020.

23. Smart L, Fawkes N, Goggin P, et al. A narrative review of the potential pharmacological influence and safety of ibuprofen on coronavirus disease 19 (COVID-19), ACE2, and the immune system: a dichotomy of expectation and reality. Inflammopharmacol. 2020;28:1141-52. https://doi.org/ 10.1007/s10787-020-00745-z.

24. Amici C, Di Coro A, Ciucci A, Chiappa L, Castilletti C, Martella V, et al. Indomethacin has a potent antiviral activity against SARS coronavirus. Antiviral Therapy. 2006;11(8):1021.

25. Lejal N, Tarus B, Bouguyon E, Chenavas S, Bertho N, Delmas B, et al. Structure-based discovery of the novel antiviral properties of naproxen against the nucleoprotein of influenza A virus. Antimicrob Agents Chemother. 2013;57(5):2231-42. 
26. Zheng W, Fan W, Zhang S, Jiao P, Shang Y, Cui L, et al. Naproxen exhibits broad anti-influenza virus activity in mice by impeding viral nucleoprotein nuclear export. Cell Rep. 2019;27(6):1875-855.e5.

27. SafiDahaj F. RE: Response to the emerging novel coronavirus outbreak: British Medical Journal Publishing Group. 2020. https://www.bmj.com/ content/368/bmj.m406/rapid-responses. Accessed 12 June 2020.

28. ClinicalTrials.gov. Efficacy of addition of naproxen in the treatment of critically ill patients hospitalized for COVID-19 infection (ENACOVID). 2020. https://clinicaltrials.gov/ct2/show/NCT04325633. Accessed 12 June 2020. 